\title{
Dois estados existenciais na poética drummondiana
}

Douglas Bernardes Romão | UFMG

Resumo: Tomando o poema "A Flor e a Náusea" como um ponto de partida, este trabalbo investigará a provável presença de duas atitudes existenciais na poética de Drummond. Parece que estas posturas criam um paradigma estrutural que reaparece em vários outros poemas e estabelece as bases para uma adequada compreensão da provável atitude pessimista.

Palavras-chave: existencialismo, hermenêtica, poesia.

\section{Introdução}

Existem duas opções hermenêuticas para a análise da obra poética de Drummond. Uma que tenta atribuir uma significação própria aos poemas e aos livros, considerando-os per se. Para esta perspectiva, a busca da unidade da obra gera uma incapacidade de percepção dos aspectos peculiares, diferenciais e independentes de cada poema ou livro. A análise das singularidades de sentido procederá imanentemente ao texto do poema ou do livro, não havendo interferência de outro sentido já estabelecido em regiões outras da obra.

A outra opção hermenêutica consiste em entrelaçar os vários elementos poéticos recorrentes em toda a obra, caracterizados por uma repetitio poética e capazes de criar constantes de significação, as quais se transmutam ou permanecem mais ou menos estáticas no decorrer da obra. Por esta perspectiva, uma análise assim holista da obra permite identificar um padrão de sentido, ou 
melhor, um paradigma. Este, por sua vez, constituir-se-á em critério de desvelamento hermenêutico de cada poema ou livro. Estabelece-se, portanto, uma exigência de coerência entre cada poema ou livro com tal paradigma.

As duas opções parecem legítimas e colocam a questão acerca do caminho poético de Drummond: apenas um ou vários caminhos? Além de legítimas, elas não são mutuamente excludentes.

Parece que os argumentos a favor da unidade da obra drummondiana mostram-se mais plausíveis. O tema da morte, p. ex., recebe um desenvolvimento fabuloso em toda a obra. ${ }^{1}$ O tema da memória, a ironia, o telurismo, a poetização do cotidiano, a percepção conflituosa do amor, uma experiência existencial de angústia (componente de uma possível atitude pessimista), todos estes elementos aparecem mais e mais recorrentes no caminho poético de Drummond.

Por outro lado, há argumentos contra a unidade da obra. A construção de uma poesia politicamente participante em A rosa do povo encontra uma ruptura drástica em Claro enigma. Ruptura condicionada pela própria imersão no momento histórico. Imersão que gera o efeito contrário a si mesma: Les événements m'ennuient, diz a epígrafe de Claro enigma. Ademais, embora não compartilhando com o ideário da vanguarda experimentalista da década de sessenta, Drummond parece romper a tônica poética ancorada na linguagem cotidiana e estabelece em "Isso e Aquilo" (In: Lição das coisas) um malabarismo vocabular.

Enfim, a investigação que este trabalho propõe, a partir do poema "A Flor e a Náusea", não adotará a priori uma ou outra das opções hermenêuticas mencionadas. Procurará efetuar ajustes destas opções, utilizando o critério da singularidade do poema ou livro quando o critério do holismo não funcionar bem e vice-versa. Proceder-se-á dessa maneira a fim de que o método hermenêutico se amolde ao sentido imanente do texto, ao invés do contrário.

\section{Os estados existenciais}

A metáfora da flor, bem como seus correlatos, apresenta-se recorrente na obra de Drummond: "em verde, sozinha,/ antieuclidiana,/ uma orquídea forma-se"; "Aproveitem. A última/ rosa desfolha-se"; "Esta rosa é

1. WILLIANS, 1986. p. 21-37.

2. Áporo. In: A rosa do povo.

3. Anúncio da Rosa. In: A rosa do povo. 
definitiva,/ ainda que pobre". ${ }^{4}$ Muitas outras ocorrências da metáfora poderiam ser citadas, muitas vezes com matiz de sentido diferencial, como em "Declaração de Amor" (In: A paixão medida).

No poema "A Flor e a Náusea", a metáfora da flor é introduzida, subitamente, após uma demora em divagações introspectivas. Na rua ("vou de branco pela rua cinzenta"), lugar do cotidiano, da vida pública, do comum, há uma reflexão angustiada sobre o tempo presente e sobre uma autopercepção. Reflexão esta que já estava prenunciada em sua estrutura no verso "vou de branco pela rua cinzenta", pois que "vou de branco" está a indicar uma percepção de si e da "rua cinzenta", do cotidiano e do tempo presente.

Pois é durante este caminhar na rua, que é ao mesmo tempo uma deambulação introspectiva, que se encontra a flor: "Uma flor nasceu na rua!" Tal evento engendra um desfazimento da pesarosa predominância de uma forma de vida, "rompe o asfalto", manifestando sua incompatibilidade com o curso frenético do cotidiano, "Façam completo silêncio, paralisem os negócios". 10 Um cotidiano do tempo pobre e das fezes. ${ }^{11}$ Há, pois, uma incompatibilidade

\section{Dissolução. In: Claro enigma.}

5. Soneto da perdida esperança. In: Brejo das almas; Contemplação do banco. In: Claro enigma; Os rostos imóveis. In: José; Eterno. In: Fazendeiro do ar; Elegia. In: Fazendeiro do ar, Canto órfico. In: Fazendeiro do ar; Girassol. In: Brejo das almas; Ar. In: A vida passada a limpo.

6. A flor e a náusea. In: A rosa do povo.

7. A fusão entre a percepção de si e do tempo presente parece ser reforçada pelo verso "Melancolias, mercadorias espreitam-me" (A flor e a náusea. In: $A$ rosa do povo), devido à concomitância das palavras 'melancolia', que se refere à psyché, e 'mercadorias', que se refere à 'rua'. O mesmo recurso para indicar tal fusão é empregado no verso, do mesmo poema: "O tempo pobre, o poeta pobre". Não bastasse isso, explicita-se a fusão no verso: "fundem-se no mesmo impasse." (A flor e a náusea. In: $A$ rosa do povo).

8. A flor e a náusea. In: A rosa do povo.

9. A flor e a náusea. In: A rosa do povo. A metáfora asfalto é explicitada, ainda que parcialmente, pelas palavras tédio, nojo e ódio no verso, do mesmo poema: "É feia. Mas é uma flor. Furou o asfalto, o tédio, o nojo e o ódio".

10. A flor e a náusea. In: A rosa do povo.

11. "O tempo é ainda de fezes, mas poemas, alucinações e espera./ O tempo pobre (...)", A flor e a náusea. In: A rosa do povo. 
entre o que rompe e o que é rompido, de modo que a coexistência deles se mostra improvável. ${ }^{12}$

Portanto, no poema há dois momentos, o da náusea (da primeira à sexta estrofe) e o da flor (da sétima à nona estrofe). Percebe-se, pois, que a metáfora da flor é melhor entendida se contraposta ao seu momento antagônico. Não seria o caso de supor que o sentido indicado na metáfora da flor tenha surgido a partir de seu sentido antagônico, pois a flor nasceu na rua, não da rua.

Se compararmos a estrutura discursiva de "A Flor e a Náusea" com a de "A Passagem da Noite", ambos do mesmo livro, é possível detectar um paralelismo, pois este último poema também apresenta uma estrutura composta por dois momentos: a primeira estrofe se refere a um estado, sintetizado pela metáfora da noite, que é suprimido, ou ainda, rompido, na segunda estrofe, por um outro estado, sintetizado pela metáfora do dia que surge. O dia irrompe na noite.

Ora, dado que no poema "Ar" (In: A vida passada a limpo) a metáfora da rosa apresenta-se contraposta à metáfora da noite, ${ }^{14}$ é possível sustentar que, respeitados os matizes diferenciais, o sentido do momento sintetizado pela metáfora da flor, no poema "A Flor e a Náusea", encontra uma correspon-dência com o sentido do momento sintetizado pela metáfora do dia que surge, no poema "A Passagem da Noite". Por outro lado, há um paralelismo entre o momento da náusea e o momento da noite. Esta associação entre as metáforas da flor e do dia que surge e entre as metáforas da noite e da náusea torna-se mais surpreendente no poema "Anúncio da Rosa" (In: A rosa do povo), pois que nele há uma correlação entre flor e aurora ${ }^{15}$ e uma indicação do antago-

12. Percebe-se que nesta incompatibilidade encontra-se anunciada a crítica sóciopolítica presente em $A$ rosa do povo, que pode também ser evidenciada em Anúncio da Rosa, do mesmo livro: "Por preço tão vil mas peça, como direi, aurilavrada,/ não, é cruel existir em tempo assim filaucioso./ Injusto padecer exílio, pequenas cólicas cotidianas,/ oferecer-vos alta mercância estelar e sofrer vossa irrisão".

13. "Mas salve, olhar de alegria!/ E salve, dia que surge!", Passagem da Noite. In: A rosa do povo.

14. "Nesta cova da noite,/ sabe o gesto a alfazema./ O que antes inebriava/ era a rosa do poema", Ar. In: A vida passada a limpo.

15. Anúncio da rosa. In: A rosa do povo: "Uma só pétala resume auroras e pontilhismos". 
nismo entre flor e noite: "pois jamais virão pedir-me, eu sei, o que de melhor se compôs na noite". ${ }^{16}$ Além disso, ressalte-se que este último verso reforça que a flor surge no asfalto, não do asfalto, que o dia que surge irrompe na noite.

Destarte, infere-se que a compreensão do sentido da metáfora da flor encontra-se não somente dependente do sentido de náusea, mas também do sentido da metáfora da noite.

Esta metáfora, recorrente em vários poemas de Drummond, ${ }^{17}$ com toda sua múltipla carga de sentido, constitui-se como um dos elementos caracterizadores de um comportamento pessimista presente na poética drummondiana. Logo, percebe-se que a exegese de "A Flor e a Náusea" há de considerar tanto um contexto pessimista, embutido no momento da náusea, quanto uma discursividade poética que tenta engendrar uma disposição contraposta à perspectiva pessimista, talvez com um impulso de superação ou negação da mesma.

Além disso, consideremos o título "Passagem da Noite". Nele se indica a noção de trânsito e de movimento, que no texto do poema expressará a sucessão de dois estados existenciais. Seja indicando um trânsito súbito, seja um trânsito feito com maiores mediações, esta noção de passagem encontra-se presente em outros poemas de Drummond. ${ }^{19}$

Assim, depreende-se que há três aspectos a serem considerados no poema "A Flor e a Náusea": o que caracteriza uma perspectiva pessimista, o que indica a superação ou negação dela e o que realiza o trânsito (mesmo que súbito) entre estes dois aspectos.

16. Anúncio da rosa. In: A rosa do povo.

17. Sentimento do mundo. In: Sentimento do mundo; A noite dissolve os homens. In: Sentimento do mundo; A bruxa. In: José; Anoitecer. In: A rosa do povo; Anúncio da rosa. In: A rosa do povo; Dissolução. In: Claro enigma; Habilitação para a noite. In: Fazendeiro do ar; Elegia. In: Fazendeiro do ar; Ar. In: Vida passada a limpo.

18. Pelo emprego da expressão superação poder-se-ia supor que este estado consiste em um derivado do pessimismo. Não parece ser este o caso, pois que a idéia de superação é apenas um efeito deste estado quem se contrapõe ao pessimismo.

19. Poema da Purificação. In: Alguma poesia; Aurora. In: Brejo das almas; Soneto da perdida esperança. In: Brejo das almas; Castidade. In: Brejo das almas; A noite dissolve os homens. In: Sentimento do mundo; A bruxa. In: José; Passagem do ano. In: A rosa do povo; Áporo. In: A rosa do povo; O homem; As viagens. In: Impurezas do branco; Parolagem da vida. In: Impurezas do branco. 
Este último aspecto não consiste em um terceiro estado existencial distinto dos dois outros, tampouco uma disposição que contenha elementos da perspectiva pessimista e elementos da superação dela. Deriva, isto sim, da contraposição entre estes dois estados. Contraposição que lhes realça o sentido próprio, de modo que a intensidade e significação de um aumentam e se evidenciam quando ele é colocado perante o outro. Assim, é o trânsito entre os dois estados existenciais que resulta da diferença entre eles, e não o contrário.

\section{A unidade}

Esta contraposição de estados existenciais não leva com segurança a supor que há uma dicotomia, uma tensão inconciliável. Podemos conjecturar que o momento da flor ou do dia que surge e o momento da náusea ou da noite contrapõem-se novamente, mediante as palavras drama e flora, na segunda estrofe de "Soneto da Perdida Esperança". Contudo, parece haver uma unidade entre os dois estados existenciais, demarcada pela palavra princípio.

Através da idéia de fusão ("Vou subir a ladeira/ em que os caminhos se fundem"), fusão que conduz a um princípio ("Todos eles conduzem ao/ princípio do drama e da flora"), parece plausível interpretar princípio como indicando um uno originário e originante no qual a contraposição se desfaz e os estados tornam-se indiferenciados.

Esta noção de unidade indiferenciada dos contrários também comparece na última estrofe de "Morte do Leiteiro". . O leite, metáfora da vida, e o sangue, metáfora da morte, fundem-se. A contraposição entre vida e morte e a subseqüente fusão levam-nos a supor que o estado existencial caracterizado pela perspectiva pessimista (noite, náusea) está associado à noção de morte e

20. "Vou subir a ladeira lenta/ em que os caminhos se fundem./ Todos eles conduzem ao/ princípio do drama e da flora." (Soneto da perdida esperança. In: Brejo das almas.

21. "Da garrafa estilhaçada,/ no ladrilho já sereno/ escorre uma coisa espessa/ que é leite, sangue... não sei./ Por entre objetos confusos, mal redimidos da noite,/ duas cores se procuram,/ suavemente se tocam,/ amorosamente se enlaçam,/ formando um terceiro tom/ a que chamamos aurora." (Morte do Leiteiro. In: $A$ rosa do povo). 
o estado de superação deste pessimismo (flor, dia que surge), à noção de vida. Há um aspecto de mortificação em um e de vivificação em outro. ${ }^{22}$

\section{Caracterização da perspectiva pessimista}

Da estrofe primeira à sexta, o eu-poético se põe num monólogo que elabora uma descrição, sempre mediada pela condição da subjetividade, das circunstâncias que o angustiam, a ponto de causar náusea. ${ }^{23}$ Circunscrito, cerceado, ${ }^{24}$ percebendo que não é muito agradável o que o circunda, ${ }^{25}$ o eupoético encontra-se num impasse: sabendo ser certo o enjôo, deve continuar nesta situação. Do contrário, surge, a partir do reconhecimento da fragilidade, ${ }^{26}$ a pergunta sobre se a revolta contra tal situação encontrará energia suficiente. ${ }^{2}$

O tempo encontra-se também num impasse: a época da completa justiça não adveio, o presente ainda é péssimo. ${ }^{28}$

Destarte, o impasse do tempo e o do eu-poético são idênticos: ${ }^{29}$ consistem no reconhecimento de uma tensão, ou seja, enquanto não advém uma situação favorável, permanece a condição péssima.

22. Esta conjectura apresenta-se problemática porque a fusão de vida e morte, no poema Morte do leiteiro, engendra uma unidade chamada aurora. Esta metáfora em alguns poemas parece estar conjugada com o sentido do estado contraposto ao pessimismo (Aurora. In: Brejo das almas; Passagem da Noite. In: $A$ rosa do povo). Contudo, não supomos, pelas peculiaridades de Morte do leiteiro, ser mais adequado interpretar aurora na mesma significação de flor e dia que surge. Mas isto pode se manifestar falho.

23. A flor e a náusea. In: A rosa do povo: "Devo seguir até o enjôo?"

24. A flor e a náusea. In: A rosa do povo: "Preso a (...) e a (...)".

25. A flor e a náusea. In: A rosa do povo: “(...) rua cinzenta”.

26. A flor e a náusea. In: $A$ rosa do povo: "(...), sem armas, (...)"

27. A flor e a náusea. In: A rosa do povo: "Posso, sem armas, revoltar-me?".

28. A flor e a náusea. In: A rosa do povo: "Olhos sujos no relógio da torre:/ Não, o tempo não chegou de completa justiça./ O tempo é ainda de fezes, maus poemas, alucinações e espera."

29. A flor e a náusea. In: A rosa do povo: "O tempo pobre, o poeta pobre/ fundem-se no mesmo impasse". 
Com um sentimento de futilidade e ausência de sentido em suas condutas para se justificar, ${ }^{30}$ somado à solidão, ${ }^{31}$ reconhecendo uma situação de não-cura, ${ }^{32}$ o eu-poético desabafa, tristemente, numa disposição quase niilista. ${ }^{33}$

Tudo isto engendra um tédio, que o poeta regurgita. ${ }^{34} \mathrm{O}$ reconhecimento de uma existência insípida ${ }^{35}$ conjuga-se com a constância dos erros. ${ }^{36}$ Ademais, o que permanece de apreciável em um eu mínimo é o ódio anárquico. ${ }^{37}$

São estes, pois, os vários ladrilhos que compõem o mosaico da perspectiva pessimista: angústia, náusea, cerceamento, desconforto, impasse, fragilidade, presente péssimo, futilidade, solidão, não-cura, tristeza, niilismo, tédio, existência insípida, constância dos erros, eu mínimo.

Tais características permitem sustentar a hipótese de que este comportamento pessimista nas seis primeiras estrofes depende de uma interrelação entre mundo e subjetividade. A partir desta inter-relação, realiza-se uma descrição tanto do mundo quanto da subjetividade, fundindo-os numa percepção/compreensão que surge desta própria descrição.

Infere-se, pois, que o pessimismo drummondiano parece diferir do de Schopenhauer, visto que este considera que o mundo em si mesmo, em sua essência, é a fonte de dor, sofrimento e tédio, ao passo que, em Drummond,

30. A flor e a náusea. In: A rosa do povo: "Em vão me tento explicar, (...)".

31. A flor e a náusea. In: A rosa do povo: "(...) os muros são surdos/ (...)/ Nenhuma carta escrita nem recebida".

32. A flor e a náusea. In: A rosa do povo: "O sol consola os doentes e não os renova".

33. A flor e a náusea. In: A rosa do povo: "As coisas. Que tristes são as coisas, consideradas sem ênfase."

34. A flor e a náusea. In: A rosa do povo: "Vomitar esse tédio sobre a cidade". O pronome demonstrativo está a indicar que o tédio é configurado pelos elementos da descrição, feita nas estrofes anteriores.

35. A flor e a náusea. In: A rosa do povo: "Quarenta anos e nenhum problema/ resolvido, sequer colocado".

36. A flor e a náusea. In: A rosa do povo: "Crimes suaves, que ajudam a viver./ Ração diária de erro, distribuída em casa".

37. A flor e a náusea. In: A rosa do povo: "Pôr fogo em tudo, inclusive em mim./ Ao menino de 1918 chamava anarquista./ Porém meu ódio é o melhor de mim./ Com ele me salvo/ e dou a poucos uma esperança minima" (grifos nossos). A sobreposição do pronome indireto (mim) com o adjetivo (mínima), criando uma rima, permite supor a idéia de eu mínimo. 
tal como se depreende dos seis primeiros parágrafos de "A Flor e a Náusea", não há um discurso essencialista sobre o mundo. Se houver um pessimismo, ele depende mais das circunstâncias de inter-relação entre mundo e subjetividade e da descrição advinda destas circunstâncias.

Por não haver um discurso essencialista, parece ser melhor determinar o pessimismo de "A Flor e a Náusea" como um estado existencial sobre o qual não incide a característica de fixidez, podendo, então, tornar-se provisório.

Contudo, a caracterização da perspectiva pessimista em "A Flor e a Náusea" parece contrastar com outros poemas que contêm afirmações essencialistas, que se aproximam das teses schopenhauerianas. Isto gera uma situação de ambivalência na caracterização deste comportamento pessimista da poética drummondiana, o qual ora se manifesta com caráter relacional e dependente da descrição que se faz do mundo e ora se apresenta como essencialista.

Cumpre ressaltar que, nestes poemas de cunho essencialistas, o pessimismo não se apresenta compatível com uma possível provisoriedade, ou melhor, não se contrapõe a uma possível negação de si mesmo, nem à noção de trânsito rumo a sua negação ou superação. ${ }^{39}$ Dessa forma, tais poemas não apresentam o pessimismo como algo contraposto a uma outra noção, tal como ocorre com as metáforas da flor e da náusea, do dia que surge e da noite.

38. Epigrama para Emílio Moura. In: Alguma poesia: "(que a vida não presta)"; Canção do berço. In: Sentimento do mundo: "Também a vida é sem importância"; A noite dissolve os homens. In: Sentimento do mundo: "O mundo não tem remédio..."; Tristeza no céu. In: José: "Por que fiz o mundo? Deus se pergunta/ e se responde: Não sei"; Consolo na praia. In: A rosa do povo: "À sombra do mundo errado/ murmuraste um protesto tímido"; Cantiga de enganar. In: Claro enigma: "o mundo não vale o mundo (...) /o mundo, valer não vale"; Cantiga de enganar. In: Claro enigma: "O mundo não tem sentido/ (...)/ Meu bem, o mundo é fechado,/ se não for antes vazio./ $\mathrm{O}$ mundo é talvez: e é só./ Talvez nem seja talvez."

39. Seja feita exceção ao poema A noite dissolve os homens (In: Sentimento do mundo), em que a afirmação essencialista "O mundo não tem remédio..." é seguida da metáfora aurora, correspondente, no caso, às metáforas flor e dia que surge. Contudo, parece plausível supor que a afirmação "O mundo não tem remédio..." não se apresenta como essencialista, visto que nos versos "A noite anoiteceu tudo.../ O mundo não tem remédio.../ Os suicidas tinham razão" as reticências estão a indicar uma relação de conseqüência, ou seja, a noite anoiteceu tudo e, em conseqüência, o mundo não tem remédio e, em conseqüência, os suicidas tinham razão. Logo, o fato de o mundo não ter remédio deriva de ter acontecido o que a metáfora noite indica. 


\section{Caracterização da disposição antagônica à perspectiva pessimista}

Como que de inesperado e de súbito, o estado existencial caracterizado pelo pessimismo é desfeito. O eu-poético, pela primeira vez, manifesta comoção maior em contraposição a todo o tédio e monotonia anteriores. ${ }^{40} \mathrm{~A}$ inter-relação entre mundo e subjetividade se altera.

Ocorre uma modificação de toda a rotina de uma existência, tornada impregnada pelo cotidiano e pelo esquecimento de aspectos da existência capazes de nos vivificar (ou seja, pelo esquecimento da flor). Modificação de abrupto: “(...) rompe o asfalto".

Como indicado acima, a metáfora da flor encontra-se associada com as metáforas do dia que surge e da aurora. Dessa forma, é possível observar esta modificação abrupta de toda a rotina de uma existência no poema "Aurora" (In: Brejo das Almas), pois que a atitude pessimista caracterizada pela metáfora da noite é expulsa pela aurora, ${ }^{42}$ e no poema "A Bruxa" (In: José) existe, na subjetividade do eu-poético, um tumulto que combate para instaurar uma nova atitude. ${ }^{4}$

Percebe-se, então, quando a intensidade da angústia e da tristeza se agiganta, nestes poemas em que há a contraposição entre o pessimismo e seu contrário, o surgimento de um princípio de vivificação, uma energia que robustece a existência.

Esta estrutura dinâmica entre dois estados existenciais presente em "A Flor e a Náusea" reflete-se em outros poemas como "Passagem da Noite" (In: $A$ rosa do povo), no qual o sentimento da alegria de viver é recuperado e recomposto, e também "Áporo" (In: A rosa do povo), adiante explicitada.

40. Há apenas um ponto de exclamação em todo o texto. Ponto este que indica esta comoção maior. Na terceira estrofe, no fim da qual era de se esperar uma exclamação, o tédio, a melancolia e a indiferença perante o mundo impedem uma comoção maior.

41. A flor e a náusea. In: A rosa do povo.

42. Aurora. In: Sentimento do mundo: "(...) expulsando a treva noturna”.

43. A bruxa. In: José: "Essa presença agitada/ querendo romper a noite". 
A partir disto tudo, é possível descrever a metáfora da flor como um princípio de vivificação que, influindo na dinâmica da subjetividade, gera uma disposição alegre, de modo a afirmar a positividade da existência.

Pelo menos no poema "A Flor e a Náusea", é possível sustentar que o estado existencial demarcado por ser antagônico a uma disposição pessimista apresenta-se fugaz, frágil e instável. Além do motivo de que são poucas as estrofes dedicadas à flor e mais numerosas as que tratam da náusea, parece que na penúltima estrofe são indicadas características de fragilidade da flor. ${ }^{45}$ Por outro lado, ela apresenta uma "forma insegura". Ademais, existe uma ameaça à flor indicando a proximidade disto que a metáfora da noite indica. ${ }^{47}$

Existe também um motivo mais sutil. O surgimento da flor acontece às cinco horas da tarde, ${ }^{48}$ ou seja, a flor surge no limiar do dia, logo vem a noite.

A hipótese relativa à fragilidade e fugacidade disto que a metáfora da flor indica é reforçada no poema "Anúncio da Rosa" (In: A rosa do povo) pelos versos: "Imenso trabalho nos custa a flor/ (...)/ Primavera não há mais doce, rosa tão meiga/ onde abrirá? (...)/ (...)/ Vêde o caule/ traço indeciso/ (...)", e principalmente pela última estrofe: "Aproveitem. A última/ rosa desfolha-se".

\section{O mistério ou a razão}

A estrutura de "A Flor e a Náusea" reaparece em "Áporo" (In: $A$ rosa do povo): as seis primeiras estrofes daquele poema correspondem aos quartetos deste e as três derradeiras daquele aos tercetos deste. Além disso, a

44. Passagem da noite. In: A rosa do povo: "Mas salve, olhar de alegria!/ E salve, dia que surge!/ (...)/ Existir: seja como for/ (...)/ Clara manhã, obrigado,/ o essencial é viver". Geralmente é atribuída à metáfora da flor a noção de esperança. Mas supomos que a potência da metáfora da flor é melhor descrita como indicando a positividade e afirmação da existência.

45. A flor e a náusea. In: A rosa do povo: "Sua cor não se percebe/ Suas pétalas não se abrem./ seu nome não está nos livros./ É feia. Mas é realmente uma flor".

46. A flor e a náusea. In: A rosa do povo: "e lentamente passo a mão nessa forma insegura".

47. A flor e a náusea. In: A rosa do povo: "(...) nuvens maciças avolumam-se”.

48. A flor e a náusea. In: $A$ rosa do povo: "Sento-me no chão da capital do país às cinco horas da tarde". 
metáfora da noite encontra-se presente no segundo quarteto e a da flor, no segundo terceto. Até mesmo a ruptura entre os dois momentos é drástica e súbita, ${ }^{49}$ tal como em "A Flor e a Náusea". Uma orquídea estranha ${ }^{50}$ rompe a regularidade, ${ }^{51}$ assim como uma flor feia ${ }^{52}$ rompe o cotidiano, impregnado das significações de tédio, nojo e ódio.

Neste soneto, evidencia-se que, no ápice da intensidade da angústia e da perplexidade misturada de pessimismo e niilismo, um estado existencial antagônico surge, acontece. Por outras palavras, no momento da aporia, ${ }^{53} \mathrm{O}$ enigma se desfaz.

Mas que labirinto, que enigma é este? Uma hipótese razoável para tal indagação pode ser encontrada no poema "Rola Mundo" (In: A rosa do povo), no qual encontram-se os versos: "E vi minha vida toda/ contrair-se num inseto".

A metáfora do inseto se repete no poema imediatamente seguinte, "Áporo": "Um inseto cava". Assim, o problema, o labirinto, o enigma é a própria vida!

Existem, pois, duas metáforas conflituantes em "Áporo", a do inseto e a da orquídea. Aquela, disposta no primeiro verso, esta, no último. Desse modo, pode-se sustentar que o poema indica uma transformação que segue dois pólos, inseto e flor. Uma vida "se desata", outra "forma-se".

Assim, nos poemas analisados em que há dois estados existenciais, e a transição entre eles, dada a correspondência da estrutura destes poemas com

49. Áporo. In: A rosa do povo: "Eis que o labirinto/ (oh razão, mistério)/ presto se desata".

50. Áporo. In: A rosa do povo: "em verde, (...)".

51. Áporo. In: A rosa do povo: "antieuclidiana".

52. A flor e a náusea. In: A rosa do povo: "É feia. Mas é realmente uma flor/ (...)/ É feia. Mas é uma flor. Furou o asfalto, o tédio, o nojo e o ódio"

53. Áporo. In: A rosa do povo: "sem achar escape".

54. Áporo. In: A rosa do povo: "Eis que o labirinto/ (oh razão, mistério)/ presto se desata:". Supomos razoável utilizar a palavra enigma devido a uma associação com labirinto.

55. O paralelismo entre os dois pólos é surpreendente, pois que os dois versos "Um inseto cava" e "uma orquídea forma-se" seguem a mesma estrutura: artigo indefinido, substantivo, verbo.

56. Áporo. In: A rosa do povo.

57. Áporo. In: A rosa do povo. 
a de "Áporo", pode-se afirmar que ocorre o advento de uma vida alegre, cândida, vigorosa e esperançosa por sobre outra caracterizada pelos adjetivos que marcam a metáfora do asfalto: "o tédio, o nojo e o ódio". 58

Mas qual o motivo, o impulso, o fundamento ou a justificativa pelos quais ocorre este trânsito? Em "Áporo" um verso tenta responder esta pergunta: "(oh razão, mistério)". Verso complicadíssimo: a razão do trânsito é um mistério, ou o mistério do trânsito é a razão dele, ou o explicável (a razão) e o insondável (o mistério) conjugam-se?

Nosso juízo parece balouçar entre tais hipóteses, sem decidir entre elas. Contudo, o poema "Lembrete" (In: Corpo) parece ajudar neste trilema: "Se procurar bem, você acaba encontrando/ não a explicação (duvidosa) da vida,/ mas a poesia (inexplicável) da vida".

Poema repleto de conseqüências. Reforça a hipótese lançada acima de que o enigma é a vida e contrapõe explicação, duvidosa, à poesia, inexplicável. Isto permite sustentar que o enigma da vida que se desata ocorre por meio de algo que transcende à capacidade de explicação: o mistério da poesia.

Além disso, este poema acrescenta ao estado existencial antagônico ao comportamento pessimista a metáfora (se assim pudermos dizer) da poesia, pelo que passaremos a intitular tal estado antagônico de poético, que "inunda minha vida inteira".

E não consideramos irrazoável supor que estado poético apresentase como catártico e patético, dada a associação da idéia de catarse e pateticidade à metáfora da rosa, no poema "Anúncio da Rosa". 60

\section{Conclusão}

Caso plausível, a hermenêutica empreendida mostrou-nos que, se houver um comportamento pessimista na poética drummondiana, ele se integra numa rede de tensão com um estado existencial que lhe é antagônico: de um lado, a negação da existência e, de outro lado, a sua afirmação e positividade.

58. A flor e a náusea. In: A rosa do povo.

59. Poesia. In: Alguma poesia: "Mas a poesia deste momento/inunda minha vida inteira".

60. Anúncio da rosa. In: A rosa do povo: "ela [a rosa] é sete flores, qual mais fragrante, todas exóticas,/ todas histórias, todas catárticas, todas patéticas." 
Os poemas "A Flor e a Náusea" e "Anúncio da Rosa" permitem sugerir, pelo menos neles mesmos, que a afirmação e positividade da existência apresentamse demarcadas pelas características da fugacidade, fragilidade e instabilidade.

$O$ antagonismo destes estados existenciais, se assim pudermos dizer, parece não se restringir a uma tensão inconciliável, pois que nos poemas "Soneto da Perdida Esperança" e "Morte do Leiteiro" há pistas razoáveis que indicam uma possível unidade, na qual os dois estados se encontram indiferenciados.

Nos poemas analisados, pelo menos, a tensão indicada corresponde a um comportamento da subjetividade, que se encontra associado a uma descrição do mundo: a cada estado existencial, corresponderia um comportamento e uma descrição.

Nos poemas, em que há um trânsito entre os estados antagônicos, parece não haver um discurso essencialista sobre o mundo, de modo que o pessimismo é relacional. Mas esta afirmação não pode se estender para a totalidade da obra, pois esta contém alguns poemas de cunho essencialista. Talvez (isto é apenas conjectura) o melhor seja considerar esta ambivalência (ora relacional, ora essencialista) como característica deste possível pessimismo.

Por fim, nestes poemas analisados, observou-se uma estrutura discursiva recorrente que instaura uma reflexão e problematização do enigma da própria vida, segundo os dois termos de estados existenciais, um de acentuado aspecto pessimista e outro, antagônico, possivelmente caracterizado como poético, catártico e patético. 
Abstract: By taking the poem A Flor e a Nausea as a point of departure, this work will investigate the probable presence of two existencial atittudes in Drummond's poetic. It seems that these postures create a structural paradigm which reappears in several otherpoems and establishes the basis for an adequate understanding of the probable pessimist attitude.

Key words: existencial, atitude, poetry, pessimism.

$$
\text { Referências Bibliográficas }
$$

ANDRADE, C. Drummond de. Nova reunião. Rio de Janeiro: José Olympio, 1983. Corpo. Rio de Janeiro: Record, 1998.

SANT'ANNA, Affonso R. de. Carlos Drummond de Andrade. Análise de obra. Rio de Janeiro: Editora Documentário, 1977.

SANTIAGO, Silviano. Carlos Drummond de Andrade. Petrópolis: Vozes, 1976.

WILLIAMS, Frederick G.; PACHÁ, Sergio (Ed.). Carlos Drummond de Andrade and his generation. Santa Barbara/University of California: Bandana Books, 1986. 